\title{
Conflito socioambiental entre a comunidade Porto do Capim e o parque ecológico
}

\author{
Social and environmental conflict between the Porto do Capim community and the ecological park \\ Conflicto social y ambiental entre la comunidad Porto do Capim y el parque ecológico
}

Recebido: 20/09/2021 | Revisado: 01/10/2021 | Aceito: 05/10/2021 | Publicado: 09/10/2021

\author{
Ana Luíza Félix Severo \\ ORCID: https://orcid.org/0000-0002-7768-1399 \\ Universidade Federal de Campina Grande, Brasil \\ E-mail: analuizafelix@yahoo.com.br \\ Erivaldo Moreira Barbosa \\ ORCID: https://orcid.org/0000-0001-7479-1827 \\ Universidade Federal de Campina Grande, Brasil \\ E-mail: erifat@terra.com.br
}

\begin{abstract}
Resumo
A pesquisa científica busca investigar o conflito socioambiental na comunidade Porto do Capim localizado no bairro do Varadouro, João Pessoa/Paraíba por meio da gestão municipal verticalizada na Ação Civil Pública ambiental. A metodologia aplicada denomina-se hermenêutica jurídica, a qual será interpretada por meio de laudos técnicos e Inquérito Civil. Contata-se que o conflito existe por se tratar de área de preservação ambiental que pode ser transformada em um parque ecológico caso a comunidade residente, desde a década de 1930, seja realocada. Constata-se que a comunidade Porto do Capim foi reconhecida por meio de laudos técnicos por se tratar de comunidade tradicional, o que daria o direito de decidir, tanto por meio de legislação extravagante, como alienígena, onde deseja se fixar e continuar com os costumes. Conclui-se que há interconexões legais para dar visibilidade aos dois interesses a fim de fortalecer a preservação ambiental e cultural, colaborando para o fortalecimento local.
\end{abstract}

Palavras-chave: Conflito socioambiental; Comunidade; Área de preservação.

\begin{abstract}
The scientific research seeks to investigate the socio-environmental conflict in the Porto do Capim community located in the Varadouro neighborhood, João Pessoa/Paraíba through the municipal management verticalized in the environmental Public Civil Action. The methodology applied is called legal hermeneutics, which will be interpreted through technical reports and the Civil Inquiry. It is noted that the conflict exists because it is an environmental preservation area that can be transformed into an ecological park if the resident community, since the 1930s, is relocated. It appears that the Porto do Capim community was recognized through technical reports as it is a traditional community, which would give the right to decide, both through extravagant and alien legislation, where it wants to settle and continue with the customs. It is concluded that there are legal interconnections to give visibility to the two interests in order to strengthen environmental and cultural preservation, contributing to local strengthening.
\end{abstract}

Keywords: Socioenvironmental conflict; Community; Preservation area.

\begin{abstract}
Resumen
La investigación científica busca investigar el conflicto socioambiental en la comunidad de Porto do Capim ubicada en el barrio de Varadouro, João Pessoa / Paraíba a través de la gestión municipal verticalizada en la Acción Civil Pública Ambiental. La metodología aplicada se denomina hermenéutica jurídica, la cual será interpretada a través de informes técnicos y la Investigación Civil. Se nota que el conflicto existe porque es un área de preservación ambiental que puede transformarse en un parque ecológico si la comunidad residente, desde la década de 1930, es reubicada. Parece que la comunidad de Porto do Capim fue reconocida a través de informes técnicos por ser una comunidad tradicional, lo que le daría el derecho a decidir, tanto a través de una legislación extravagante como ajena, dónde quiere establecerse y continuar con las costumbres. Se concluye que existen interconexiones legales para dar visibilidad a los dos intereses con el fin de fortalecer la preservación ambiental y cultural, contribuyendo al fortalecimiento local.

Palabras clave: Conflicto social y ambiental; Comunidad; Área de preservación.
\end{abstract}

\section{Introdução}

Fundada como cidade e, inicialmente, chamada de Filipéia de Nossa Senhora das Neves - Paraíba, o município de João Pessoa - Paraíba sempre manteve relação com o rio Sanhauá ${ }^{1}$, pois é onde se localiza o marco zero e também foi

\footnotetext{
1 Um dos principais afluentes do Rio Paraíba, que corta os municípios de João Pessoa e Cabedelo, ambos municípios da Paraíba.
} 
construído o primeiro porto, denominado de Porto do Varadouro o qual nomeia o bairro.

$\mathrm{Na}$ localização do porto do Varadouro estava presente a parte econômica da região, pois todas as mercadorias chegavam no bairro do Varadouro, concentrando, portanto, trabalhadores formais e informais, diretos e indiretos. Ou seja, aqueles que eram empregados da área ou trabalhavam no comércio da região e os que sobreviviam com uma renda variável com negócios populares próximos ao porto. Popularmente, a área ficou conhecida como Porto do Capim devido à extensa quantidade de capim que era desembarcada para alimentação dos animais de tração da cidade.

Apesar da importância econômica para a região, o porto do Varadouro ou do Capim foi desativado por causa do assoreamento do rio Paraíba (Sanhauá), o qual impedia a passagem das embarcações. O novo porto mudou de município e de nome, localizado em Cabedelo - Paraíba, chamado de Porto de Cabedelo.

Após a mudança, a região do porto do Varadouro não passou por um processo de revitalização ambiental e tampouco houve uma readaptação do comércio popular para o novo porto. Por causa disso, a população que antes sobrevivia da economia indireta e informal gerada pelo porto do Varadouro passou a ocupar a área das margens do Rio Sanhauá, que não possuía mais a vegetação nativa, bem como os arredores do bairro Varadouro, o que fez modificar a forma econômica para sobreviver e também a relação com o meio ambiente. Posto que, a população que antes era de pequenos comerciantes passou a depender do mangue e do rio Sanhauá, o que proporcionou mudança no cenário paisagístico do bairro Varadouro com a recuperação da mata nativa de mangue às margens do rio Sanhauá.

Atualmente, a comunidade é uma das partes envolvidas no conflito socioambiental do bairro Varadouro. O eixo econômico também está na disputa, pois é também uma das vieses usadas pela gestão municipal para construir um parque com finalidade turística a fim de ocupar a área para que toda população possa usufruir dela e gerar renda para quem obtiver a concessão de exploração da área, seja com lanchonetes ou privatizando a administração o parque.

Do outro lado, está a população das comunidades, a qual reside naquela região desde o encerramento do porto do Varadouro e sobrevivem do rio Sanhauá, além de manter uma relação cultural com a localidade. Na outra ponta, está a União cuja competência legal de preservação dessas áreas foi concedida pela Constituição Brasileira de 1988 (Artigo 20, III). Ademais, é área pertencente à União haja vista que ali se localizava o porto do estado cuja cessão pública não foi repassada ao município.

Dessa forma, o conflito está entre o interesse econômico e socioambiental; de preservação da comunidade tradicional e ribeirinha ou preservação exclusivamente ambiental. O objetivo é apresentar a situação de conflito atual vivida pelas comunidades Praça 15, Frei Vital, Porto do Capim, Curtume e Vila Nassau, até o segundo semestre de 2020. O método usado será o hermenêutico ao usar laudos técnicos e documentos oficiais, como a Ação Civil Pública e o Inquérito Civil $\mathrm{n}$. 1.24.000.001117/2015-16 para interpretar esses documentos e trazer o panorama geral da área de estudo, na delimitação temporal até o segundo semestre de 2020, haja vista que a lide continua.

Com as inúmeras tentativas de fixar acordo institucional e o fracasso em manter contato com a gestão municipal, por esta ter iniciado o processo de modificação do espaço com a demolição de casas de moradores que aceitaram o acordo e se mudaram para condomínios populares, em 2019, o Ministério Público Federal ingressou com a Ação Civil Pública n. 080968326.2019.4.05.8200, cuja primeira decisão paralisou qualquer tipo de obra que esteja sendo realizada naquela região, tendo em vista que as casas são conjugadas e qualquer interferência estrutural pode prejudicar as residências vizinhas.

\section{Metodologia}

O método aplicado denomina-se hermenêutica jurídica, o qual permite interpretar todo o trajeto da pesquisa científica em alusão, a fim de "contextualizar, compreender e explicar transformações normativo-institucionais de natureza ecossistêmicas em áreas ambientais" (Barbosa e Barbosa, 2021, p. 14). Ademais, a técnica adotada é a interpretativa, a qual 
permite interpretar laudos técnicos, Ação Civil Pública e Inquérito Civil, visto que é a parte prática da hermenêutica, isto é, revela os significados dos termos jurídicos (Barbosa, 2009; Nader, 2006).

A área de estudo fica localizada no bairro do Varadouro, popularmente conhecido após a fixação das pessoas às margens do antigo porto do Varadouro. Entretanto, é preciso ressaltar que não se trata de uma comunidade, mas de cinco, denominadas de Vila Nassau, Praça 15, Porto do Capim, Curtume e Frei Vital (Figura 1).

Figura 1. Limites da área de estudo.



Fonte: Imagem adaptada de Google Earth (2020).

Para este trabalho, será simplificada pela expressão "comunidade Porto do Capim”, mas se destaca que em pesquisa mais aprofundada, cada uma dessas comunidades serão caracterizadas respeitando-se as individualidades tradicionais, culturais e históricas. Porém, o atual estudo visa analisar o conflito socioambiental da comunidade Porto do Capim o qual ocasionou na Ação Civil Pública n. 0809683-26.2019.4.05.8200.

\section{Conflito Socioambiental da Comunidade Porto do Capim}

A área de conflito legalmente é de preservação permanente e está localizada no Centro Histórico de João Pessoa (Figura 2), cujo perímetro foi extensivamente explorado desde a sua fundação até a desativação do porto do Varadouro. Após a transferência, a população que sobrevivia da economia informal e indireta gerada por aquele, fixou-se na área e passou a subsistir do mangue e do rio.

Figura 2. Limites do bairro Varadouro.



Fonte: Imagem adaptada de Google Earth (2020). 
Nesse sentido, a comunidade se formou a partir da apropriação do espaço deixado pelo antigo porto do Varadouro juntamente com os empregados que não se adequaram ao novo modelo de porto implantado na cidade de Cabedelo - Paraíba.

Além disso, não houve qualquer iniciativa de recuperação da área ou ocupação pelo poder público, tornando-o um espaço vazio em pleno centro comercial antigo da cidade. Ocorre que, por se tratar de curso de água e de um rio, a legislação ambiental brasileira (Lei Federal n. 12.651/2012, Art. 65, $\S 2^{\circ}$ ) proíbe a ocupação e a considera área de preservação permanente, ou seja, espaço que não pode haver qualquer tipo de exploração ou habitação de largura mínima de 15 metros de distância de cada lado (Figura 3).

Porém, salienta-se que a legislação veio depois da ocupação dessas comunidades, o que configura uma discussão jurídico-institucional, haja vista que o laudo técnico de comunidade tradicional e ribeirinha foi obtido recentemente (Farias, 2015). Além do que pesquisadores da área da ciência socioambiental, vem dizer que mais importante do que a área de conservação, sem processo democrático e participativo, distante dos saberes e tradições populares não agregam o diálogo de saberes e não propõem a conservação da biodiversidade e da diversidade cultural de forma transdisciplinar. Por isso, defendem como novos modelos a etnoconservação, que "devem ser densos em novos conhecimentos científicos tanto das ciências naturais quanto sociais e saberes tradicionais" (Diegues, 2019, p. 118).

Figura 3. Distância da margem do rio para a comunidade.

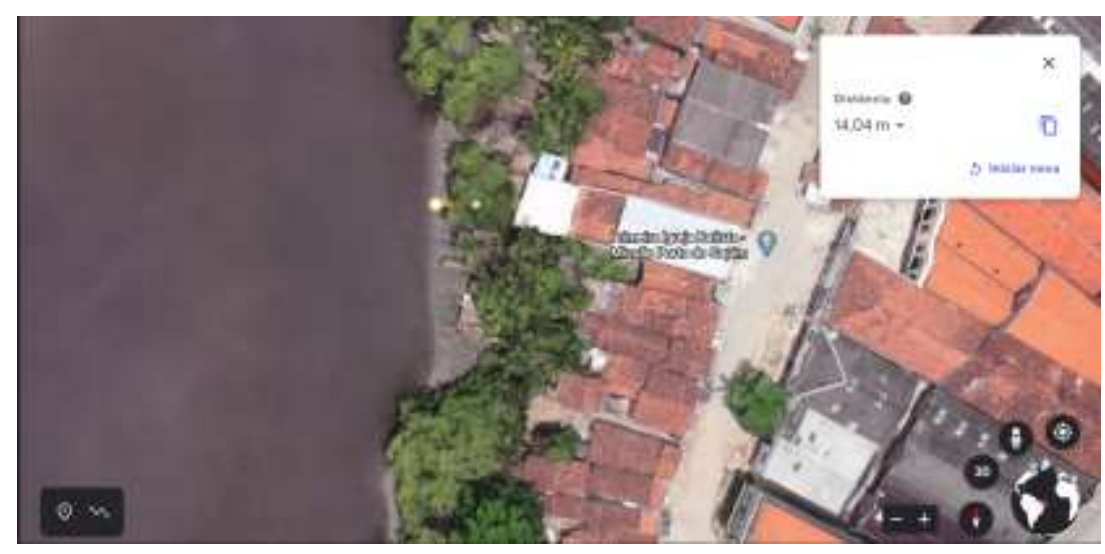

Fonte: Imagem adaptada de Google Earth (2020).

No entanto, antes da sançao da Leı rederal n. 0.9vL/1Y81, a qual trata da criaçao da estaçao ecológica e de áreas de proteção ambiental, a comunidade Porto do Capim já habitava a área e complementava a sua renda com as atividades pesqueiras. Dessa forma, como aponta Mura (2019) ao citar Mauss (1993), a comunidade assumiu o espaço e o modificou para adequar as suas necessidades, não sendo o meio ambiente o fator determinante da forma de vida social dela ${ }^{2}$.

A partir da ocupação e da necessidade de manter o leito do rio Sanhauá próprio para a subsistência da comunidade, a área passou por um processo de revitalização ambiental ganhando vegetação própria da área de mangue sob iniciativa da própria população que também modificou o espaço com construção de moradias. Isto é, a própria comunidade modificou a valoração do espaço ambiental para a sua sobrevivência.

Conforme Diegues (2019), existe a supremacia do saber quando há, em alguns setores, dúvidas sobre os benefícios que a comunidade tradicional pode trazer para a sociedade, haja visto o argumento de não possuírem a escolaridade formal.

2 Mesmo os autores conhecendo a teoria de Marcel Mauss, preferiu-se fazer este apud, por se tratar de um informe técnico elaborado a pedido do Ministério Público Federal, o qual foi juntado na Ação Civil Pública n. 0809683-26.2019.4.05.8200, a fim de complementar o parecer técnico de Ivan Soares Farias (antropólogo, analista pericial do MPF), a respeito da tradicionalidade de ocupação da comunidade do Porto do Capim, João Pessoa, Paraíba. Fábio Mura foi o coordenador desse projeto. 
Obviamente, trata-se de confronto de saberes, o qual o científico se apropria do lugar de fala dos tradicionais e embasa as decisões governamentais. Além do que, a Convenção 169 Organização Internacional do Trabalho, assegura a educação formal e tradicional, logo o debate sobre essa ótica é infrutífero e não gera o diálogo de saberes e decisões democráticas e participativas (Leff, 2010).

Dessa forma, o meio deixou de ser exclusivamente sua fonte de subsistência no conceito de produção natural, extração e consumo humano e receptor de resíduos, mas para uma mutualidade ao respeitar o ciclo reprodutivo das espécies, a vegetação contribui para o equilíbrio do mangue. Logo, pode-se dizer que a comunidade regulou de forma tradicional e informal de acordo com seus costumes o uso dos recursos naturais daquela região para que não houvesse uma escassez e, assim passassem a sobreviver do que a natureza der, ou seja, "a gestão tradicional inclui um número maior de objetivos, além dos econômicos e da eficiência técnica, englobando a qualidade de vida, a sociabilidade e os aspectos simbólicos" (Diegues, 2019, p. 122).

Portanto, serviço ambiental prestado pelas comunidades para com o meio ambiente, porém a negligência e o comodismo em mensurar esses valores vem a partir de interesse econômico em sequer analisar comparativamente os custos e benefícios para solucionar o conflito socioambiental. Ao contrário disso, os agentes de decisão buscam não implantar ou encerrar políticas públicas para que torne impossível a sustentabilidade dos recursos naturais e, assim, usar outras medidas previamente justificadas diante da degradação ambiental existente (Mota e Bursztyn, 2013).

Logo, com a desativação do Porto e nenhum projeto de revitalização ambiental no local, o espaço ficou em completo abandono, assim como toda a população dependente dele. Diante disso, ocorre a apropriação social e dos elementos da natureza quando ressignifica o espaço e passa a viver de forma semelhante aos povos ribeirinhos e tradicionais desde a década de 1940, portanto a atuação se dá "como condição de subsistência para a sua reprodução física, social e econômica, recorrendo a conhecimento herdados por tradição e reproduzido por gerações" (Farias, 2015).

Corrobora o relatório de Farias (2015), Diegues (2019, p. 119), ao escrever que o “[ ...] conhecimento tradicional pode ser definido como o saber e o saber-fazer, a respeito do mundo natural, sobrenatural, produzidos pelos povos e comunidades tradicionais, transmitidos oralmente de geração em geração". E assim também preleciona a Convenção 169 da Organização Internacional do Trabalho ao proteger o direito consuetudinário dos povos tradicionais, os valores e práticas sociais, culturais religiosas e espirituais.

Nesse sentido, vê-se semelhança do conflito socioambiental ocorrido na comunidade Porto do Capim ao caso de Jericoacoara, quando a gestão pública estadual interferiu no modo de viver do vilarejo de pescadores que ali se fixaram, para transformar em um parque de atração turística e atrair pessoas e investidores nacionais e internacionais (Brumacci e Philippi $\mathrm{Jr}, 2014)$.

Logo, é possível perceber a visão utilitarista quando os agentes de decisão tomam alguma medida baseada em maximização da utilidade do meio ambiente para gerar conforto humano e também valor econômico, porém isso é pensado de forma individual e não coletiva, bem como a distribuição da utilidade é uma satisfação individual que não envolve a sociedade, mesmo que esta seja a justificativa usada (Sen, 2010; Mota e Bursztyn, 2013).

Portanto, é importante que os tomadores de decisões envolvam a dimensão ética quando necessitarem agir em nome da vida em sociedade e não somente lancem mãos de modelagens estritamente técnicas, é preciso também que essa dimensão alcance os procedimentos científicos e o ato de legiferar (Mota e Bursztyn, 2013).

À luz do desenvolvimento sustentável foi o argumento utilizado pela defesa da gestão pública para a concretização de interpretação meramente econômica sob aquele viés e isso se dá pela falta de significância aplicada ao termo desenvolvimento sustentável, o qual fica a cargo de fatores pessoais, formação profissional, grau cultural, educação ambiental e interesse econômico (Brumacci e Philippi Jr, 2014). 
Por causa da relação com a natureza, a comunidade requer um projeto participativo que consagre a população, com a sua atividade e tudo o que a área representa para os munícipes, seja no contexto de patrimônio histórico e cultural, ou de possuir um parque ecológico no centro histórico da cidade. Tendo em vista que "a comunidade não teve acesso à participação nem o conhecimento prévio do projeto [de realocação e de construção do parque ecológico]. Seguido da geração de dificuldades de acesso ao projeto público, não respeitando a lei da transparência pública” (Silva, 2015, p. 2251).

Outrossim, o projeto de realocação proposto pela Prefeitura Municipal de João Pessoa, impactaria nas relações interpessoais e sociais, das pessoas da comunidade Porto do Capim, pois seriam destinados para residenciais prediais sem contato ou proximidade com o meio ambiente natural.

Nesse caso, configurara injustiça socioambiental, pois a comunidade depende da natureza e dos seus recursos para fugir da pobreza extrema e manter a sua subsistência. Logo, dar acesso desigual não geraria justiça e seria desproporcional, haja vista que os munícipes não dependem daquela área como as comunidades. Portanto, a geração vivente atual e as futuras seriam impactadas com a realocação, pois os ensinamentos tradicionais passados de geração em geração não seriam mais transmitidos (Souza et al, 2014).

Então, é necessário que a gestão municipal e os tomadores de decisão observem a Carta Magna sob o Artigo. 216, no que aduz sobre o patrimônio cultural, tendo-se em vista que o título de comunidade ribeirinha e tradicional considera esses povos parte formadora patrimônio histórico, artístico e cultural brasileiro; cumpram a Organização Internacional do Trabalho 169, cuja norma foi inserida no ordenamento jurídico brasileiro; participem das audiências públicas, a qual é um instrumento democrático e participativo da sociedade civil; apresentem medidas conciliatórias, entre outras.

\section{Situação Jurídico Institucional da Comunidade Porto do Capim}

A Ação Civil Pública 0809683-26.2019.4.05.8200, possui um efeito e uma audiência. No que diz respeito ao primeiro caso, dá-se com a suspensão de qualquer obra do Parque Ecológico Sanhauá, obra da gestão municipal, dentro da comunidade Porto do Capim, a partir do dia 27 de fevereiro de 2020. Sendo a decisão fruto de apelo por parte da Procuradoria-Geral do Município.

Enquanto que em relação ao segundo fato, ocorreu no dia 10 de março de 2020, a primeira audiência de conciliação em âmbito da $1^{\text {a }}$ Vara Federal, com a presença de representantes dos moradores; da Defensoria Pública da União; da Advocacia-Geral da União, que representou a Superintendência do Patrimônio da União; do Ministério Público Federal; Procuradoria do Município de João Pessoa e o atual chefe do executivo (Seção de Comunicação Social da JFPB, 2020).

Durante a audiência, os representantes das comunidades apresentaram os pedidos para a Procuradoria do Município de João Pessoa e também ao gestor, que são: i) a disponibilização de novas moradias para as famílias residentes nas áreas das obras; ii) a criação de área de comércio no local de realocação dos moradores; iii) o reconhecimento por parte da gestão municipal da condição de comunidade tradicional e ribeirinha; e, iv) a garantia de preservação das áreas de mangue independentemente do projeto a ser instalado (Seção de Comunicação Social da JFPB, 2020).

$\mathrm{O}$ que se percebe nas demandas apresentadas pela comunidade Porto do Capim é que mesmo fazendo uma interpretação restritiva dos artigos fundantes da ACP em questão. Ademais, envolvem pleito de ordem constitucional cogente, difuso e coletivo quando solicita a preservação da área de mangue em torno do Varadouro.

Por outro lado, Ministério Público Federal e a Defensoria Pública da União, avaliarão juntamente com os representantes das comunidades e demais moradores a viabilidade em aceitar as contrapropostas da gestão municipal, as quais foram: i) pagar o auxílio aluguel no valor de de $\mathrm{R} \$ 350$ mensais para as famílias que serão realocadas até a efetiva construção 
das unidades habitacionais nas imediações do Porto do Capim; ii) destinação de um imóvel da União para criar o museu da comunidade Porto do Capim³

Para melhor entendimento, faz-se necessário explicar o percurso institucional que levou o Ministério Público Federal a ingressar com a Ação Civil Pública.

Várias cidades brasileiras passaram por um processo de mudança urbana com os recentes megaeventos, como os Jogos Olímpicos, Jogos Paralímpicos, Copa do mundo de futebol masculino, Encontro mundial de jovens católicos, Panamericano, entre outros. Ocorre que, essas mudanças estão relacionadas com modificação de espaços amplamente disputados que geralmente são o centro da cidade e a alguns setores localizados em bairros nobres. $\mathrm{O}$ sentido dessas reformas são para retirar tudo o que pode tornar a cidade feia, sob o olhar de tomadores de decisão, que muitas vezes agem de forma autoritária, conservadoras e hegemônica e isso tem um nome específico chamado de gentrificação (Braga e Moraes, 2016; Diegues, 2019; Santos, 2007; Souza et al, 2014).

No que diz respeito à comunidade Porto do Capim, o que se visa é a realocação das pessoas pobres, tradicionais e ribeirinhas para lugares escondidos das cidades. Assim, a área ocupada por ela poderia ser transformada em construções urbanas voltadas para o campo empresarial, que não agrega a sustentabilidade de forma ampla, isto é, incluindo os povos dentro de seus territórios. Logo, não pode os tomadores de decisão fazer uso de instrumentos conferidos à administração pública para realocar famílias com a justificativa de que a área estará disponibilizada para a sociedade.

A justificativa dos tomadores de decisão referente ao processo de gentrificação é com base na poluição visual, desordem predial e até mesmo degradação ambiental. Nesse sentido, ao contrário o que diz o relatório da Prefeitura Municipal de João Pessoa, de que a comunidade Porto do Capim degrada o meio ambiente natural existente, outros relatórios provindos de estudantes de graduação e pós-graduação vinculados ou não ao Projeto de Extensão Universitária da Universidade Federal da Paraíba, o qual mostrou exatamente o contrário, inclusive comprova por meio de fotografias ao longo das décadas de 1910 aos anos 2000 de que a comunidade envolvida preserva e revitalizou a área natural porque precisam de um meio ambiente natural sadio e preservado para sobreviver do que extraem do mangue e perpetuar tradições de outrora (imaginário popular, dança, comida - como ensopado de marisco), portanto, percebem e definem a sua luta como socioambiental (Silva, 2015; Braga e Moraes, 2016; Máximo, 2013; Catarino et al, 20-?).

Ineditamente, o conflito socioambiental uniu diversos pesquisadores das áreas das ciências ambientais, humanas, jurídicas e sociais a concordarem com a permanência da comunidade Porto do Capim no centro histórico de João Pessoa. O que contraria a perspectiva e constatação de Diegues (2019) ao relatar sobre estudos isolados das ciências e cada uma defendendo o seu ponto de vista, sem correlacionar com as outras ciências. Apesar disso, acredita-se no acerto do autor, pois é o que ocorre via regra geral, sendo a união a exceção. Mas ele também se apresenta como otimista ao escrever que há alternativa para uma discussão inter ou transdisciplinar, é a partir da participação democrática, isto é, de estudos sobre a nova etnociência da conservação.

Ademais, foi realizado um relatório o qual verificou que a comunidade Porto do Capim que reside nesta localidade está a mais de 70 anos e, até então, preserva sua tradição como população ribeirinha (Centro de Referência em Direitos Humanos, 2015). Por causa disso, o Ministério Público realizou a perícia antropológica para verificar se a comunidade Porto do Capim é considerada ou não uma comunidade tradicional ribeirinha. Visto que, isso mudaria completamente o fundamento jurídico e teórico para ocupação por parte da Administração Pública Municipal para transformar aquela área em um atrativo turístico sob o viés de revitalização no intuito de praticar a gentrificação. Haja vista a tendência é sempre realocar os pobres

3 Até a data de finalização deste trabalho, estava previsto o prazo para manifestação sobre a audiência de conciliação até o dia 24 de março de 2020. O juiz federal da $1^{\text {a }}$ Vara ficou de decidir a necessidade de uma segunda audiência conciliatória. 
para as partes não visíveis das cidades, logo, concorda-se que "a materialização do chamado planejamento estratégico vem a partir do agenciamento da administração pública para atender a especulação predatória do capital imobiliário.” (Silva, 2015, p. 2243). Isso possibilitou ao Ministério Público Federal instaurar o Inquérito Civil 1.24.000.001117/2015-16, no ano de 2015, a fim de investigar administrativamente a atuação da gestão municipal diante deste grupo protegido por Convenção internacional o qual o Brasil é signatário.

Durante o Inquérito Civil, foram elaborados dois pareceres técnicos para laudo antropológico, sendo um da Defensoria Pública da União e o outro do Ministério Público Federal, em ambos ficaram evidenciados se tratar de população tradicional e ribeirinha caracterizando-se, portanto, cabe a Convenção 169 da Organização Internacional do Trabalho, cujo Art. $7^{\circ}$ consagra a consulta à comunidade no que diz respeito ao projeto do Parque Ecológico Sanhauá e o Art. 216, II, da Constituição Brasileira de 1988 dá o direito de criar, fazer e viver da comunidade tradicional. Além do que, a Organização Internacional do Trabalho reconhece "o direito de permanecer em seu território e continuar exercendo seu modo tradicional de vida" (Diegues, 2019, p. 122) e deveria estar acima de grandes projetos governamentais.

Outrossim, ficou demonstrado no Inquérito Civil 1.24.000.001117/2015-16 que a área em questão se trata de área de marinha, cuja propriedade é da União, a qual não deu o direito de cessão para a construção do parque. Tampouco foi realizado por parte da gestão municipal o Estudo de Impacto Ambiental e o Relatório de Impacto Ambiental, conforme se é exigido em se tratando de área de preservação. Nesse sentido, o Inquérito Civil 1.24.000.001117/2015-16 determina a abstenção do início das obras por parte da Caixa Econômica, da construtora Planes Engenharia E Construção LTDA e da gestão municipal sob provável ato de improbidade administrativa, irregularidade na cessão da área da União e observância à Convenção 169 da Organização Internacional do Trabalho e a Constituição Brasileira de 1988.

Entretanto, a gestão municipal não se absteve em iniciar o processo de desocupação pressionando de forma psicológica a comunidade Porto do Capim e, por causa disso, o MPF ingressou com a Ação Civil Pública 0809683 26.2019.4.05.8200.

A Ação Civil Pública visa "o direito à proteção territorial da comunidade tradicional ribeirinha do Porto do Capim." (Ministério Público Federal, 2019). A inicial faz uma síntese fática e registro documental de relatórios de vários órgãos os quais apontam a veracidade da permanência daquele povo enquanto parte do centro histórico da cidade de João Pessoa. Visto que, não são só os prédios que formam o patrimônio cultural, mas de matéria e imatéria e dentro deste estão o povo, a tradição, a crença e a cultura (BRASIL, 1988, Art. 216).

Além disso, a realocação não se trata de escolha da comunidade Porto do Capim, logo, ferindo a Convenção 169 da Organização Internacional do Trabalho e isto é trazido quando se expõe que "a existência de ocupação subnormal que [...] deve ser removida para outro ponto da cidade, a fim de que as obras sejam executadas." (Ministério Público Federal, 2019). Outrossim, a realocação desvinculará a relação social, econômica e histórica da comunidade tradicional e ribeirinha com o rio Sanhauá, posto que a realocação pretendida é para apartamentos em outra região da cidade. Consolidando-se, portanto, em um mega projeto higienista com características de gentrificação para atender ao apelo do setor turístico descontextualizado ou do turismo mercadológico.

O Procurador justifica a necessidade da ACP por se tratar de matéria de direito difuso e coletivo; pela atitude tomada por parte da gestão municipal em não mais dialogar com a comunidade e órgãos envolvidos (Defensoria Pública da União, Ministério Público Federal, Universidade Federal da Paraíba, Instituto do Patrimônio Histórico e Artístico Nacional, Instituto do Patrimônio Histórico e Artístico do Estado da Paraíba, Superintendência Pública da União) quando realizou o processo licitatório e contratou empresa de engenharia, bem quando notificou as famílias do Porto do Capim para a desocupação em 48 horas; também pela omissão na resposta em acatar ou não a recomendação da suspensão das obras; por iniciar obra em área da União e não possui a cessão pública; por se tratar de comunidade tradicional e ribeirinha com direito violado. 
A situação atual é de intenso conflito entre a gestão municipal e os moradores, dado que com alguns acordos realizados algumas casas foram demolidas causando danos na estrutura de residências próximas. Outro fato trazido é de que as máquinas passaram a funcionar ainda no horário de descanso daquela comunidade. Agora, com a suspensão judicial das obras o que se pretende é realizar um acordo para que ambas as partes possam participar do processo de reurbanização do local, com preservação do patrimônio histórico e cultural da comunidade Porto do Capim, bem como a defesa do meio ambiente sadio do mangue do rio Sanhauá.

\section{Considerações Finais}

A discussão acerca da defesa do espaço para a população da cidade tendo em vista o caráter histórico, há o conflito socioambiental maior do que dar acesso aos cidadãos a uma área conhecida como marco zero. O conflito envolve pessoas que ali residem desde a década de 1930 e do mangue e do rio Sanhauá conseguem a subsistência.

O território das comunidades, comprovadamente, recuperou a área degradada pelo porto do Varadouro e mantém a vegetação nativa de mangue e isso se dá pelo caráter antropológico auferido aos povos tradicionais e ribeirinhos ao se relacionar com a natureza de forma solidária, respeitando o tempo de resiliência ecológica.

Apesar de tudo isso, o interesse econômico e hegemônico tende a se tornar voz uníssona entre os tomadores de decisão com a tentativa de realocar a população para lugares mais distantes dessa relação de diálogo com o meio ambiente natural.

No entanto, a legislação brasileira incorpora a internacional e confere a esses povos o poder de decisão para escolher o local que querem concretizar suas práticas tradicionais. Nesse sentido, o Ministério Público Federal juntamente com outros órgãos e pesquisadores de diversas instituições realizaram pesquisas para averiguar a realidade socioambiental e econômica das comunidades.

Atualmente, o conflito está judicializado e espera-se resolução pacífica e conciliatória para que as partes processuais possam enfim realizar aquilo que foi acordado. E, às comunidades, possa então praticar o bem viver e continuar a produzir cultura e história pelo centro da cidade de João Pessoa. Sugere-se que pesquisadores de outras abordagens acompanhem o desenrolar do conflito socioambiental para que outros trabalhos sejam elaborados com perspectivas distintas. Assim como, pesquisadores da área ambiental possam mergulhar nos estudos do resquício de manguezal urbano o qual foi revitalizado pela comunidade Porto do Capim.

\section{Referências}

Barbosa, E. M. (2009). Gestão de recursos hídricos da Paraíba: uma análise jurídico-institucional. Tese de doutorado. Doutorado em Recursos Naturais. Universidade Federal de Campina Grande. Centro de Tecnologia e Recursos Naturais. Campina Grande, Paraíba.

Barbosa, E. M. \& Barbosa, M. de F. N. (2021). Direitos emergentes (ambiental e de águas): buscando fruições. Revista Veredas do Direito, Belo Horizonte 18 (40), 11-36. DOI http://dx.doi.org/10.18623/rvd.v18i40.1763

Braga, E. O. \& Moraes, C. G. M. S. M. (2016). Porto do Capim: lutas e estratégias de existência de uma comunidade ribeirinha no centro histórico de João Pessoa/PB. Revista Ñanduty, 4 (4), 20-52. http://ojs.ufgd.edu.br/index.php/nanduty/issue/view/189/showToc.

Brasil. Constituição da República $\quad$ Federativa $\quad$ do $\quad$ Brasil, 2168 . https://www.senado.leg.br/atividade/const/con1988/CON1988_05.10.1988/art_216_.asp.

Brunacci, A. \& Philippi Jr, A. (2014). A dimensão humana do desenvolvimento sustentável (2ª ed.). In: Educação ambiental e sustentabilidade. Philippi Jr ,A.; Pelicioni, M. C. F.(orgs.). Barueri, São Paulo: Manole.

Catarino, A. J. L.; Morais, H. B. de; Silva, M. A. F. \& Gonçalves, R. C. (20-?). Relatório técnico multidisciplinar comunidade Porto do Capim. Pró-Reitoria de Extensão (PROEX), Universidade Federal da Paraíba. Paraíba, João Pessoa

Centro de Referência em Direitos Humanos (2015). Universidade Federal da Paraíba. Centro de Ciências Jurídicas. Porto do Capim: Relatório de Violações aos Direitos Humanos. https://issuu.com/crdhufpb/docs/relat_rio_porto_do_capim. 
Research, Society and Development, v. 10, n. 13, e158101320839, 2021

(CC BY 4.0) | ISSN 2525-3409 | DOI: http://dx.doi.org/10.33448/rsd-v10i13.20839

Dantas, M. F. P. \& Vasconcelos, T. G. de V. (2016). Luta e resistência: A comunidade do Porto do Capim e as intervenções de revitalização do Centro Histórico de João Pessoa/PB. Anais do III CONEDU. http://editorarealize.com.br/revistas/conedu/anais.php.

Diegues, A. C. (2019). Conhecimentos, práticas tradicionais e a etnoconservação da natureza. Revista Desenvolvimento e Meio Ambiente. Seção especial: Diálogos de Saberes Socioambientais: desafios para epistemologias do Sul, 50, 116-126.

Farias, I. (2015). Parecer antropológico n. 03/2015. Ministério Público Federal. Procuradoria da República na Paraíba, João Pessoa.

Leff, E. (2010). Discursos sustentáveis (Tradução de Silvana Cobucci Leite). São Paulo, São Paulo: Editora Cortez, 2010.

Máximo, P. R. G. (2013). Uso e ocupação do solo e perspectivas turísticas do território do Porto do Capim, Varadouro, João Pessoa-PB. 53p. Monografia de Graduação. Universidade Federal da Paraíba, João

Pessoa.

Ministério Público Federal (2019). Inquérito Civil n. 1.24.000.001117/2015-16. Despacho n. 8592/2019. PR-PB-00029213/2019. Procuradoria da República da Paraíba. Procuradoria Regional dos Direitos do Cidadão. Procurador da República José Guilherme Ferraz da Costa.

Mota, J. A. \& Burstyn, M. (2013). O valor da natureza como apoio à decisão pública. Revista Paranaense de Desenvolvimento, Curitiba, 34 (125), $39-56$.

Mura, F. (coord.) (2019). Informe técnico sobre a tradicionalidade de ocupação da comunidade do Porto do Capim (João Pessoa - PB), UFPB, Paraíba, João Pessoa.

Nader, P. (2006). Introdução ao estudo do Direito (27 ed.). Rio de Janeiro, Rio de Janeiro: Editora Forense.

Santos, M. (2007). O espaço cidadão (7 $7^{\mathrm{a}}$ ed.). São Paulo, São Paulo: Universidade de São Paulo, 2007.

Seção de comunicação social da JFPB. Justiça Federal na Paraíba. (2020). Justiça Federal realiza audiência de conciliação sobre obras na região do Porto do Capim: Comunidade e prefeitura terão até 24 de março para se manifestarem sobre propostas recíprocas, 10 de março de 2020. http://www.jfpb.jus.br/manterNoticia?metodo=detalhar\&codigo=4014\&pagina=noticia.jsp.

Sen, A. (2010). Desenvolvimento como liberdade (Tradução de Laura Teixeira Motta e Revisão técnica de Ricardo Doninelli Mendes). São Paulo, São Paulo: Companhia das Letras.

Silva, A. F. (2015). Resistência e luta das mulheres do Porto do Capim em João Pessoa: o direito à cidade desde a perspectiva de gênero. Anais do XI Encontro Nacional da Anpege, 2243-2253.

Souza, C. M. de M; Santos, G. F. dos; Aumond, J. J. \& Gomes, A. M. (2014). Pescadores artesanais e injustiça ecológica no litoral de Santa Catarina (2ª ed.). In: Educação ambiental e sustentabilidade. Philippi Jr, A.; Pelicioni, M. C. F. (orgs.). São Paulo, Barueri: Manole. 